\title{
The central role of the Journal reaffirmed
}

\author{
Ami E. Iskandrian, MD, MACC, MASNC ${ }^{a}$ \\ a Division of Cardiovascular Diseases, Department of Medicine, University of Alabama at \\ Birmingham, Birmingham, AL
}

Received Nov 9, 2015; accepted Nov 9, 2015

doi: 10.1007/s12350-015-0335-9

In my last editor's page (January 2015), I summarized the new initiatives of the Journal in 2014. The reality is that new initiatives are just beginning, and more are on the horizon as the Journal positions itself as the heart and soul of the nuclear cardiology community, for users and providers alike.

At the outset, I would like to acknowledge the dedication and hard work of my Associate Editors, Guest Editors, Managing Editor, Publisher, and key members of the ASNC organization for their tireless efforts, suggestions, and support. I am indebted to our authors and reviewers for their tremendous contributions in providing new knowledge and new directions.

Our previous statistical consultant Inmaculada Aban, $\mathrm{PhD}$, stepped down for personal reasons. We welcome Charity J Morgan, PhD, from Department of Biostatistics at UAB Public Health School, to our editorial board. Charity will be providing short editorials on the statistical methods used in relevant papers, in addition to comments to authors. A list of changes in JNC is summarized in the Table 1.

The Journal after many years has finally succeeded in providing CME to reviewers (if requested, 3 credits per review for a maximum of 15 credits per year), as long as the reviews meet pre-specified criteria. This is a small token of our appreciation of the time and efforts spent in providing high-quality reviews that almost always enhance the scientific merits of the paper. The authors could always obtain CME from AMA directly. The mechanisms of obtaining both types have been published in the Journal.

We have initiated a series of theme articles and debates; the first debate was published in the September/

Reprint requests: Ami E. Iskandrian, MD, MACC, MASNC, Division of Cardiovascular Diseases, Department of Medicine, University of Alabama at Birmingham, 318 LHRB/ 1900 University BLVD, Birmingham, AL 35294; aiskand@uab.edu

J Nucl Cardiol 2016;23:1-3.

$1071-3581 / \$ 34.00$

Copyright (c) 2015 American Society of Nuclear Cardiology.
October issue. The second debate, focused on screening asymptomatic diabetic patients, was published in the November/December issue (2015). More are lined up for the future. We have also published a series of papers from important meetings that directly impacts our practice, such as technology (PET imaging) or concerns (ethical issues).

We publish selected proceedings from ESC, ACC, and AHA meetings. The format includes a selection of abstracts presented at the meeting in various imaging modalities (Echocardiography, cardiac MR, cardiac CT, and nuclear). The proceedings from ESC were published in the November/December 2015 issue. We are grateful to our Associate and Guest Editors and for all the authors who contribute to these series.

Some papers offer incremental new information that is worth publishing (but that does not require a fulllength manuscript style) or an important preliminary finding such as a new tracer or a new application. These are now published in a new category called "Brief Reports," which are entirely different from "Images that Teach." An example is seen in this issue.

The Mentoring at a Distance program under the leadership of Frans J. Th. Wackers, MD has had a good start and has been enthusiastically received by authors and volunteer mentors. The structure and functions of this Committee have been previously discussed.

The Journal has struggled with how to get nuclear technologists, nurses, and paramedical personnel to take a more active role and be recognized. Our initial attempt was to include them as co-authors (as long as they met authorship criteria, which we published). The response to that initiative was underwhelming to say the least. Our latest effort has seen the creation of a "Technology Corner," of which Ernest V. Garcia, $\mathrm{PhD}$, is the Section Editor, and whose committee comprises nuclear technologists. This issue contains examples of papers belonging to this section. Acknowledging the pivotal role of nuclear technologists is long overdue, as everyone knows that we cannot run our operation without their help and input.

The Journal is also planning an "International corner." It will provide news from around the world and 
Table 1. Current and planned types of manuscripts published in the Journal and other changes

\begin{tabular}{|c|c|}
\hline 1 & Original articles \\
\hline 2 & Brief reports \\
\hline 3 & Mentoring at Distance \\
\hline 4 & A quick glance at selected topics in this issue \\
\hline 5 & Reviews \\
\hline 6 & CME articles \\
\hline 7 & Editorials \\
\hline 8 & Editor's page \\
\hline 9 & Guidelines \\
\hline 10 & Nuclear cardiology in the literature \\
\hline 11 & Review of cardiovascular literature \\
\hline 12 & Summary of important contributions in preceding year \\
\hline 13 & Highlights of national and international meetings \\
\hline 14 & Debate articles \\
\hline 15 & Theme articles \\
\hline 16 & Technical corner \\
\hline 17 & International corner \\
\hline 18 & Process of translation to Spanish and other languages \\
\hline 19 & Molecular imaging corner \\
\hline 20 & Images that teach \\
\hline 21 & Letters to the editor \\
\hline 22 & $\begin{array}{l}\text { ASNC news updated and a message from the President } \\
\text { of ASNC }\end{array}$ \\
\hline 23 & $\begin{array}{l}\text { Miscellaneous: such as abstracts presented at ASNC, } \\
\text { ethical issues, etc. }\end{array}$ \\
\hline 24 & Poems, arts, photos, and quotes \\
\hline
\end{tabular}

will include translation of the abstract of the lead article in each issue to Spanish initially, and hopefully to other languages over time. Erick Alexanderson, MD, a Board member, will spearhead these efforts.

We are back to publishing selected ACC/AHA guidelines or appropriateness criteria relevant to our field as well as ASNC guidelines and white papers. When needed, we will also offer editorials and concise summaries.

We have increased the number of state-of-the-art review articles and editorials. Editorials are extremely important for highlighting the strengths and weaknesses of a contribution and to put the results in perspective while addressing future directions. The editorialists provide a great service to our field by sharing their knowledge and experience. Review articles and editorials rank among the most useful categories as rated by our readers.

The series of literature search articles in the imaging and cardiovascular fields by our Associate Editors and Board members go a long way in bringing our busy readers up-to-date information published in other major journals. Along the same lines, we provide selected abstracts in various imaging modalities (nuclear, echo,
CMR, and CT) that have just been presented at the ACC, AHA, and ESC annual conventions.

The art pieces, photos, poems, and meaningful quotes are welcomed new features that help soften the angles of physics and science. I encourage you all to keep sending me your best. These will now be listed in the table of contents and on the cover page.

To share their experience and expertise, and to offer a more varied approach, I have asked each Associate and Guest Editor to write the editor's page for the past 2 years. This will be the third year of continuing this practice. I have been impressed by the quality and diversity of their insights, and I know our readers have been as well.

Starting with this issue, we will publish "A quick glance at selected topics in this issue" to highlight selected articles published within the issue. A similar feature is used by many other journals under different headings. We will continue to publish a summary of important contributions published in the Journal during the preceding year. Other new "corners or silos" in the works include a molecular imaging corner, selected power point slides that summarize a paper, and video talks and interviews featuring the authors of select articles. 
This year, around the time of the ASNC annual scientific sessions, we conducted a reader survey in order to gauge your reactions to JNC and its new initiatives. The results of this survey will be published in the ASNC newsletter; we were very pleased to discover that they support the central role of the Journal in the nuclear cardiology community. Some highlights and key findings of the survey: JNC was ranked as the most important journal for respondents in meeting their information needs for cardiac imaging; review articles, guidelines, controversies, reviews of imaging literature, reviews of $\mathrm{CV}$ literature, and summaries of best papers were all well received. Overall, the changes implemented over the last year or so were mostly judged as favorable by the readers.

The 2015 ANSC meeting included the presentation of the Zaret-Beller Award for the top reviewer, as well as awards for the best clinical and best basic research papers, which by now have become valued traditions of the Journal.

As always, please write to us with your ideas about how we could serve you better in the coming year. As custodians of the Journal, our biggest priorities are our readership and our commitment to providing the highest quality educational material. 